\title{
Neucrin is a novel neural-specific secreted antagonist to canonical Wnt signaling
}

\section{$\operatorname{AUTHOR}(\mathrm{S}):$}

Miyake, Ayumi; Takahashi, Yohsuke; Miwa, Hiroyuki; Shimada, Akihiko; Konishi, Morichika; Itoh, Nobuyuki

\section{CITATION:}

Miyake, Ayumi ... [et al]. Neucrin is a novel neural-specific secreted antagonist to canonical Wnt signaling. Biochemical and Biophysical Research Communications 2009, 390(3): 1051-1055

\section{ISSUE DATE:}

2009-12

URL:

http://hdl.handle.net/2433/89636

\section{RIGHT:}

c 2009 Elsevier Inc. All rights reserved.; この論文は出版社版でありませ ん。引用の際には出版社版をご確認ご利用ください。; This is not the published version. Please cite only the published version. 
Neucrin is a novel neural-specific secreted antagonist to canonical Wnt signaling

Ayumi Miyake $^{1 *}$, Yohsuke Takahashi ${ }^{1}$, Hiroyuki Miwa, Akihiko Shimada, Morichika Konishi, and Nobuyuki Itoh ${ }^{*}$

Department of Genetic Biochemistry, Kyoto University Graduate School of Pharmaceutical Sciences, Sakyo, Kyoto 606-8501, Japan

${ }^{1}$ These authors contributed equally to this work.

*Corresponding author. Address: Ayumi Miyake, Department of Genetic Biochemistry, Kyoto University Graduate School of Pharmaceutical Sciences, Yoshida-Shimoadachi, Sakyo, Kyoto 606-8501, Japan. Tel: +81 75753 4539. Fax: +81 75753 4600. E-mail: miyakea@pharm.kyoto-u.ac.jp or Nobuyuki Itoh, Department of Genetic Biochemistry, Kyoto University Graduate School of Pharmaceutical Sciences, Yoshida-Shimoadachi, Sakyo, Kyoto 606-8501, Japan. Tel: +8175753 4540. Fax: +81 75753 4600. E-mail: itohnobu@pharm.kyoto-u.ac.jp 


\section{ABSTRACT}

A gene encoding a novel secreted protein in mice, humans and zebrafish was identified, and named Neucrin. Mouse Neucrin consists of 343 amino acids with a cysteine-rich domain in its carboxyl terminal region. The positions of ten cysteine residues in the cysteine-rich domain are similar to those of Dickkopfs (Dkks), secreted Wnt antagonists. However, whereas Dkks have two cysteine-rich domains, Neucrin has only one. Neucrin as well as Dkks bound to LDL receptor-related protein 6 and inhibited the stabilization of cytosolic $\beta$-catenin, indicating that Neucrin is an antagonist of canonical Wnt signaling. Mouse Neucrin expression was not detected in any major tissues in the adult, but was detected in developing neural tissues, including the brain and spinal cord. The expression pattern of Neucrin is distinct from that of any Dkk. Neucrin is a unique secreted Wnt antagonist that is predominantly expressed in developing neural tissues.

Keywords: Wnt, antagonist, brain, neucrin, Dkk, mouse 


\section{Introduction}

During the development of multicellular organisms, various signaling pathways are activated in a highly coordinated manner to ensure proper morphogenesis. Secreted signaling molecules such as fibroblast growth factors (Fgfs), bone morphogenic proteins (Bmps), Wnts, and Hedgehogs (Hhs) play crucial roles in morphogenesis by influencing the intracellular signaling events of their neighbors from a distance. Wnts comprise a large family of growth factors that are involved in diverse processes in development and disease $[1,2]$. Wnts are subjected to negative regulation by numerous secreted antagonists including the secreted frizzled-related protein (sFRP), Wnt inhibitory factor 1 (Wif1), Cerberus, Wise and the Dickkopf (Dkk) family [3]. The Dkk gene family comprises at least four members in vertebrates ( $D k k 1-D k k 4)$. Dkks contain two conserved cysteine-rich domains. The cysteine-rich domains display a characteristic spacing of cysteine residues and other conserved amino acids. Outside of the domains, Dkks show little sequence similarity [3-5].

Many secreted signaling proteins and their regulators play crucial roles in cell proliferation and differentiation. The identification and characterization of novel secreted signaling proteins are expected to provide new insights into the mechanism of cell proliferation and differentiation. We identified a number of genes encoding novel secreted proteins from mouse cDNAs of unknown function in the DNA databases. Among these proteins, we reported Ectodin, Neudesin, and Brorin. Ectodin plays crucial roles in tooth morphogenesis [6,7]. Neudesin and Brorin are potentially involved in neural development [8-10]. We also have identified a novel secreted protein, Neucrin, which has a cysteine-rich domain. The positions of ten cysteine residues in this domain are similar to those of Dkks that are secreted Wnt antagonists. We report here the identification of Neucrin, a novel secreted antagonist to canonical Wnt signaling, which is predominantly expressed in developing neural tissues. 


\section{Materials and methods}

Identification of mouse and human Neucrin. Amino acid sequences predicted from mouse cDNAs of unknown function in nucleotide sequence databases were randomly analyzed using PSORT (Prediction of Protein Sorting Signals and Localization Sites in Amino Acid Sequences). Many cDNAs encoding putative secreted proteins were identified. Full-length cDNAs were isolated by polymerase chain reaction (PCR) with the embryonic cDNA as a template and cloned into a vector DNA, $p G E M-T$ (Promega). We termed one of them mouse Neucrin.

Human NEUCRIN $c$ DNAs was also identified in a homology-based search of human cDNA or genomic DNA sequences in nucleotide sequence databases with the amino acid sequence of mouse Neucrin.

Forced Expression of mouse neucrin in CHO-S cells. The mouse Neucrin cDNA with a DNA fragment encoding a Myc-tag (EQKLISEEDL) and a His ${ }_{6}$-tag at the 3' terminus of the coding region was constructed in a vector DNA, $p c D N A 3.1(+)$ (Invitrogen). CHO-S cells $\left(2.3 \times 10^{5}\right.$ cells/ml) (Gibco) in a serum-free medium, CHO-S-SFM (Gibco), were plated on 24-well dishes $(0.5 \mathrm{ml} /$ well $)$, cultured at $37^{\circ} \mathrm{C}$ for $16 \mathrm{~h}$, and then transfected with the Neucrin cDNA (0.8 mg) using Lipofectamine 2000 (Invitrogen) at $37^{\circ} \mathrm{C}$ for $4 \mathrm{~h}$. After the transfection, CHO-S cells were further cultured in fresh CHO-S-SFM at $37{ }^{\circ} \mathrm{C}$ for $72 \mathrm{~h}$. The cells were lysed and the protein with the Myc tag in the lysate or medium was detected by Western blotting with anti-Myc tag antibody (Cell Signaling) as described [11].

Reverse transcription-polymerase chain reaction. RNA was extracted from mouse tissues or mouse embryos using an RNeasy Mini Kit (QIAGEN). cDNA was amplified from the RNA by reverse transcription-polymerase chain reaction (RT-PCR) using the following 
primers ( $5^{\prime}$ primer / 3' primer): mouse Neucrin, 5'-gacagggagagccaatggca-3' / 5'caccaactagggcactagatgt-3' (1058 bp fragment); mouse Gapdh [10].

In situ hybridization. Section in situ hybridization was preformed using mouse embryos as described [10]. An ${ }^{35}$ S-labeled mouse Neucrin sense or antisense RNA probe was transcribed from NotI or SphI-digested mouse Neucrin cDNA cloned in the $p G E M-T$ using T7 or SP6 RNA polymerase with uridine 5 ' $-\alpha-\left[{ }^{35}\right.$ S $]$ thiotriphosphate $(\sim 30$ $\mathrm{TBq} / \mathrm{mmol}$ ) (Amersham Biosciences), respectively. Neucrin binding assay. $m f z 8 C R D-I g G / p R K 5$ was described previously [12]. LRP6N$I g G / p c D N A 3.1(+)$ was generated by fusion of the extracellular domain of mouse LRP6 with an IgG tag. The Brorin-IgG/pcDNA3.1(+) construct contains the full-length Brorin [10] fused with an IgG tag. The human embryonic kidney cell line 293T was maintained in high-glucose Dulbecco's modified Eagle's medium (DMEM) containing 10\% fetal bovine serum (FBS) in $5 \% \mathrm{CO}_{2}$ at $37^{\circ} \mathrm{C}$. $293 \mathrm{~T}$ cells were transfected with the DNA using FuGene6 reagent (Roche) according to the manufacturer's protocol. Advanced DMEM:F12 (1:1) serum-free medium was used to obtain the conditioned medium (CM). Neucrin, Brorin, fz8CRD and LRP6N proteins in CM were examined by Western blotting with anti-Myc antibody or anti-human IgG antibody $(1: 4,000)$ (Jackson Immunoresearch). Brorin-IgG, fz8CRD-IgG, or LRP6N-IgG in CM was conjugated with Protein A Sepharose beads (GE Healthcare). After one wash with PBS/0.3M NaCl and three washes with PBS, the beads were incubated with CM containing Neucrin-Myc at $4^{\circ} \mathrm{C}$ overnight, washed with PBS/0.3M NaCl four times, and then boiled for $5 \mathrm{~min}$ in gel loading buffer. The elutes were examined by Western blotting. $\beta$-catenin stabilization assay. 293T cells were grown in 35-mm wells in DMEM containing $10 \%$ FBS and were $\sim 80 \%$ confluent at the time of the assay. Cells were washed twice with serum-free DMEM and incubated at $37^{\circ} \mathrm{C}$ with $1 \mathrm{ml}$ of $\mathrm{CM}$ containing Neucrin-Myc. After a 3-h incubation, the culture was supplemented with recombinant mouse Wnt-3a for a further $2 \mathrm{~h}$. The cells were then washed with PBS, lysed in $50 \mu \mathrm{l}$ of 
lysis buffer (0.1\% Saponin, $25 \mathrm{mM}$ HEPES, and $75 \mathrm{mM}$ Potassium Acetate), and centrifuged at $15,000 \mathrm{rpm}$ for $5 \mathrm{~min}$ at $4^{\circ} \mathrm{C}$. Protein concentrations were determined using the Bio-Rad protein assay reagent (Bio-Rad Laboratories). Aliquots containing $5 \mathrm{~g}$ of protein were examined by Western blotting with anti- $\beta$-catenin antibody (H-102; Santa Cruz). Equal loading of the samples was confirmed by probing the blots with mouse anti$\beta$-actin antibody (1:2,500) (Sigma).

\section{Results}

\section{Identification of mouse and human Neucrin}

We identified mouse embryonic cDNAs encoding novel putative secreted proteins by analyzing amino acid sequences predicted from mouse cDNAs of unknown function in the nucleotide sequence database with a computer program for the prediction of protein localization sites in cells (PSORT). The full-length cDNAs were isolated by PCR with mouse embryonic cDNA as a template. One of them encodes a putative secreted protein of 343 amino acids with a putative signal sequence ( 24 amino acids) at its amino-terminus (GenBank $^{\mathrm{TM}}$ accession code AB301918) (Fig. 1A). We termed it Neucrin (neural tissuespecific cysteine-rich protein), as it was predominantly expressed in mouse embryonic neural tissues as described below. Neucrin has a cysteine-rich domain in its carboxyl terminal region (Fig. 1A). Positions of ten cysteine residues in the cysteine-rich domain are similar to those in the second cysteine-rich domains of members of the Dkk family, although the amino acid sequence of the domain is less similar to that in Dkks (Fig. 1B). Outside of the cysteine-rich domain, Neucrin is unique with no primary structural similarity to any known proteins including Dkks.

Human Neucrin cDNA (AB301919) was also identified in a homology-based search of human cDNA sequences in the nucleotide sequence databases with the amino acid 
sequence of mouse Neucrin. The amino acid sequence of human Neucrin (349 amino acids) is highly similar ( 76\% identity) to that of mouse Neucrin (Fig. 1A).

\section{Forced expression of mouse Neucrin in cultured cells}

To examine whether Neucrin is a secreted protein, mouse Neucrin cDNA was expressed in cultured cells. CHO-S cells expressing mouse Neucrin protein with a Myctag were created. The Neucrin CHO-S cells were cultured for $72 \mathrm{~h}$. No bands were detected in either the lysate or culture medium of control CHO-S cells (Fig. 1C). A major band of $\sim 48 \mathrm{kDa}$ was detected in the lysate of the Neucrin CHO-S cells. The observed molecular mass was larger than the calculated molecular mass of the recombinant Neucrin protein $(\sim 38 \mathrm{kDa})$. A major band of $\sim 58 \mathrm{kDa}$ with some minor bands of $52 \sim 31 \mathrm{kDas}$ was also detected in the medium, indicating that Neucrin is a secreted protein (Fig. 1C). The molecular mass in the medium was larger than the molecular mass in the cell lysate, indicating that Neucrin protein might be subjected to post-translational modification during the secretion process. Neucrin has a potential glycosylation site at amino acid position $258(\mathrm{~N})$. Neucrin also has several dibasic sites that might be subjected to proteolytic processing (Fig. 1A).

\section{Expression of Neucrin in mouse embryos and adult tissues}

Neucrin expression in mouse adult tissues (postnatal day 49, P49) was examined by RT-PCR (Fig. 2A). Neucrin expression was not detected in any adult tissues examined. However, it was significantly detected in embryos at embryonic day 13.5 (E13.5). The spatial expression pattern of Neucrin in mouse embryos at E13.5 and E18.5 was also examined by in situ hybridization. The expression of Neucrin, shown by red grains, was predominantly detected in the developing neural tissues including the brain and spinal cord (Fig. 2C, E). In contrast, essentially no grains were detected in these regions with the sense probe as a control (Fig. 2D, F). 
As Neucrin expression was detected in mouse embryonic brain, its expression was also examined in the brain during embryonic and postnatal development (E13.5 P49). Neucrin was abundantly expressed in the embryonic brain at all the stages examined (Fig. 2B). However, its expression in the postnatal brain significantly decreased with development (Fig. 2B). These results indicate that Neucrin is preferentially expressed in the brain at embryonic and early postnatal stages.

Binding of Neucrin to LRP6 receptor and Neucrin's inhibition of $\beta$-catenin's stabilization

Dkks are secreted proteins that negatively regulate the canonical Wnt signaling pathway, indicating that Neucrin might also have this function. Dkk1 is a high-affinity ligand for LDL receptor-related protein (LRP) 6 and does not bind to the Frizzled (Fz) family receptors [13]. We examined whether Neucrin bound to the extracellular domain of LRP6 or Fz8. A Myc-fused form of mouse Neucrin (Neucrin-Myc), an IgG-fused form of the cysteine-rich domain (CRD) of mouse Fz8 (Fz8CRD-IgG) or the extracellular domain of mouse LPR6 (LRP6N-IgG), and an IgG-fused form of Brorin, a Bmp antagonist, (Brorin-IgG) as a negative control were prepared from transiently transfected 293 T cells. CMs were subjected to immunoprecipitation followed by Western blotting. Neucrin was co-immunoprecipitated with LRP6N-IgG but not with Fz8CRD-IgG or Brorin-IgG (Fig. 3A).

Canonical Wnt signaling is mediated by the transcriptional effecter $\beta$-catenin. Activation of the canonical Wnt signaling pathway results in the stabilization of cytosolic $\beta$-catenin. We examined whether the inhibition of $\beta$-catenin's stabilization by Neucrin occurred in the extracellular environment. The steady-state level of $\beta$-catenin protein in 293T cells was examined. Treatment of the cells with Neucrin CM inhibited the stabilization of cytosolic $\beta$-catenin triggered by Wnt3a protein (Fig. 3B). This result clearly suggests that degradation of cytosolic $\beta$-catenin was induced by extracellular Neucrin. 


\section{Discussion}

Wnts play crucial roles in diverse processes in development and disease [1,2]. Wnts are subjected to negative regulation by numerous secreted antagonists [3]. Dkks are secreted Wnt antagonists. The $D k k$ gene family consists of at least four members in vertebrates (Dkk1-Dkk4). Dkk genes encodes proteins of $\sim 250-350$ amino acids, which are subjected to posttranslational modifications including glycosylation and proteolytic processing. Dkks contain two conserved cysteine-rich domains including the $\mathrm{N}$-terminal (first) domain and C-terminal (second) domain. The cysteine-rich domains display a characteristic spacing of cysteine residues and other conserved amino acids. Outside of the domains, Dkks show little sequence similarity [3]. The second domain alone is sufficient for Wnt antagonist activity [4,5].

We identified Neucrin, a novel secreted protein, in mice and humans. The amino acid sequences of the two proteins are significantly similar. Neucrin has only one cysteine-rich domain in its carboxyl terminal region. The positions of ten cysteine residues in the cysteine-rich domain are similar to those in the second cysteine-rich domains of members of the Dkk family, although the amino acid sequence of the domain is less similar to that of Dkks. In addition, except for the positions of cysteine residues, Neucrin is unique with no primary structural similarity to any known proteins including Dkks. These results indicate that the functional domain of Neucrin might be located in the carboxyl terminal region including the cysteine-rich domain.

Dkk1 that has cysteine-rich domains in their carboxyl terminal region is an LRP6 ligand and inhibits the canonical Wnt/ $\beta$-catenin signalling by preventing the formation of the Fz-LRP6 complex induced by Wnt [4]. Neucrin that has a cysteine-rich domain in its carboxyl terminal region also bound to LRP6 but not Fz8. Therefore, Neucrin is also an LRP6 ligand. Furthermore, exogenously added Neucrin also inhibited Wnt3a's stabilizing 
effect on $\beta$-catenin. These results indicate that neucrin is a secreted Wnt antagonist and inhibits canonical Wnt/ $\beta$-catenin signaling by binding to LRP6.

Gene knockout studies suggest roles of Wnts in neural development in mice. The brain's development is greatly impaired in Wnt-1 knockout mice [14,15]. The development of the hippocampus is also impaired in Wnt-3a knockout mice [16]. Furthermore, Wnt-1 and Wnt-3a double knockout mice have an additional reduction in the size of the rostral hindbrain [17]. These results indicate that Wnt signaling plays crucial roles in neural development.

Dkkl was originally identified as a gene conferring Spemann head organizer activity in Xenopus embryos [18]. Dkk1 is specifically expressed in the anterior mesendoderm, which has a potent head-inducing activity. In zebrafish, $d k k 1$ is also expressed in organizer derivatives of gastrulating embryos [19]. Overexpression of $d k k 1$ in zebrafish embryos suppresses defects in the development of forebrain, eyes, and notochord in boz mutants, which have organizer deficiencies [20]. Dkkl knockout mice lack head structures anterior to the mid-hindbrain boundary [21]. Although Dkk2 knockout mice are viable, they are blind [22]. These results also indicate that Wnt signaling plays crucial roles in neural development.

Neucrin expression was not detected by RT-PCR in major adult tissues including the brain in mice. In contrast, in mouse embryos, Neucrin is predominantly expressed in neural tissues including the brain and spinal cord. The embryonic neural tissue-specific expression pattern of Neucrin is distinct from that of members of the Dkk family [3,23]. These results indicate that neucrin potentially has roles in neural development.

During our present study in progress, we have learned that Neucrin is identical with draxin, which is a secreted repulsive guidance protein for spinal cord and forebrain commissures and shares no homology with known guidance cues [24]. draxin deficient mice show defasciculation of spinal cord commissural axons and absence of forebrain commissures [24]. Recently, it also has been reported that Wnts function as axon 
guidance molecules [25]. These findings suggest that Neucrin/draxin potentially functions as a repulsive guidance molecule by inhibiting Wnt signaling.

In conclusion, Neucrin is a unique secreted Wnt antagonist identified in mice and human. Neucrin is predominantly expressed in developing neural tissues. The present findings should provide new insights into roles of Wnt signaling in neural development.

\section{Acknowledgements}

This work was supported by a Grant-in-Aid for Creative Scientific Research from the Ministry of Education, Science, Culture and Sports of Japan (N.I.) and the Takeda Science Foundation (A.M.).

\section{References}

[1] C.Y. Logan, R.Nusse, The Wnt signaling pathway in development and disease, Annu. Rev. Cell Dev. Biol. 20 (2004) 781-810.

[2] A.J. Mikels, R. Nusse, Wnts as ligands: processing, secretion and reception, Oncogene 25 (2006) 7461-7468.

[3] C. Niehrs, Function and biological roles of the Dickkopf family of Wnt modulators, Oncogene 25 (2006) 7469-7481.

[4] B.K. Brott, S.Y. Sokol, Regulation of Wnt/LRP signaling by distinct domains of Dickkopf proteins, Mol. Cell. Biol. 22 (2002) 6100-6110.

[5] L. Li, J. Mao, L. Sun, W. Liu, D. Wu, Second cysteine-rich domain of Dickkopf-2 activates canonical Wnt signaling pathway via LRP-6 independently of disheveled, J. Biol. Chem. 277 (2002) 5977-5981.

[6] Y. Kassai, P. Munne, Y. Hotta, E. Penttila, K. Kavanagh, N. Ohbayashi, S. Takada, I. Thesleff, J. Jernvall, N. Itoh, Regulation of mammalian tooth cusp patterning by 
ectodin, Science 309 (2005) 2067-2070.

[7] J. Laurikkala, Y. Kassai, L. Pakkasjarvi, I. Thesleff, N. Itoh, Identification of a secreted BMP antagonist, ectodin, integrating BMP, FGF, and $\mathrm{SHH}$ signals from the tooth enamel knot, Dev. Biol. 264 (2003) 91-105

[8] I. Kimura, M. Yoshioka, M. Konishi, A. Miyake, N. Itoh, Neudesin, a novel secreted protein with a unique primary structure and neurotrophic activity, J. Neurosci. Res. 79 (2005) 287-294.

[9] I. Kimura, M. Konishi, A. Miyake, M. Fujimoto, N. Itoh, Neudesin, a secreted factor, promotes neural cell proliferation and neuronal differentiation in mouse neural precursor cells, J. Neurosci. Res. 83 (2006) 1415-1424.

[10] N. Koike, Y. Kassai, Y. Kouta, H. Miwa, M. Konishi, N. Itoh, Brorin, a novel secreted bone morphogenetic protein antagonist, promotes neurogenesis in mouse neural precursor cells, J. Biol. Chem. 282 (2007) 15843-15850.

[11] T. Yamashita, M. Konishi, A. Miyake, K. Inui, N. Itoh, Fibroblast growth factor (FGF)-23 inhibits renal phosphate reabsorption by activation of the mitogen-activated protein kinase pathway, J. Biol. Chem. 277 (2002) 28265-28270.

[12] J.C. Hsieh, A. Rattner, P.M. Smallwood, J. Nathans, Biochemical characterization of Wnt-Frizzled interactions using a soluble, biologically active vertebrate Wnt protein, Proc. Natl. Acad. Sci. USA 96 (1999) 3546-3551.

[13] M.V. Semënov, K. Tamai, B.K. Brott, M. Kühl, S. Sokol, X. He, Head inducer Dickkopf-1 is a ligand for Wnt coreceptor LRP6, Curr. Biol. 11 (2001) 951-961.

[14] A.P. McMahon, A. Bradley, The Wnt-1 (int-1) proto-oncogene is required for development of a large region of the mouse brain, Cell 62 (1990) 1073-1085.

[15] K.R. Thomas, M.R. Capecchi, Targeted disruption of the murine int-1 proto-oncogene resulting in severe abnormalities in midbrain and cerebellar development, Nature 346 (1990) 847-850. 
[16] S.M. Lee, S. Tole, E. Grove, A.P. McMahon, A local Wnt-3a signal is required for development of the mammalian hippocampus, Development 127 (2000) 457-467.

[17] M. Ikeya, S.M. Lee, J.E. Johnson, A.P. McMahon, S. Takada, Wnt signalling required for expansion of neural crest and CNS progenitors, Nature 389 (1997) 966-970.

[18] A. Glinka, W. Wu, H. Delius, A.P. Monaghan, C. Blumenstock, C. Niehrs, Dickkopf1 is a member of a new family of secreted proteins and functions in head induction, Nature 391 (1998) 357-362.

[19] M. Shinya, C. Eschbach, M. Clark, H. Lehrach, M. Furutani-Seiki, Zebrafish Dkk1, induced by the pre-MBT Wnt signaling, is secreted from the prechordal plate and patterns the anterior neural plate, Mech. Dev. 98 (2000) 3-17.

[20] H. Hashimoto, M. Itoh, Y. Yamanaka, S. Yamashita, T. Shimizu, L. Solnica-Krezel, M. Hibi, and T. Hirano, Zebrafish Dkk1 functions in forebrain specification and axial mesendoderm formation, Dev. Biol. 217 (2000) 138-152.

[21] M. Mukhopadhyay, S. Shtrom, C. Rodriguez-Esteban, L. Chen, T. Tsukui, L. Gomer, D.W. Dorward, A. Glinka, A. Grinberg, S.P. Huang, C. Niehrs, J.C. Belmonte, H. Westphal, Dickkopfl is required for embryonic head induction and limb morphogenesis in the mouse, Dev. Cell 1 (2001) 423-434.

[22] M. Mukhopadhyay, M. Gorivodsky, S. Shtrom, A. Grinberg, C. Niehrs, M.I. Morasso, H. Westphal, Dkk2 plays an essential role in the corneal fate of the ocular surface epithelium, Development 133 (2006) 2149-2154.

[23] V.E. Krupnik, J.D. Sharp, C. Jiang, K. Robison, T.W. Chickering, L. Amaravadi, D.E. Brown, D. Guyot, G. Mays, K. Leiby, B. Chang, T. Duong, A.D. Goodearl, D.P. Gearing, S.Y. Sokol, S.A. McCarthy, Functional and structural diversity of the human Dickkopf gene family, Gene 238 (1999) 301-313.

[24] S.M. Islam, Y. Shinmyo, T. Okafuji, Y. S u, B. Nasre, G. Ahmed, S. Zhang, S. Chen, K. Ohta, H. Kiyonari, T. Abe, S. Tanaka, R. Nishinakamura, T. Terashima, T. Kitamura, H. Tanaka, Draxin, a repulsive guidance protein for spinal cord and 
forebrain commissures, Science 323 (2009) 388-393.

[25] L. Li, B.I. Hutchins, K. Kalil, Wnt5a induces simultaneous cortical axon outgrowth and repulsive axon guidance through distinct signaling mechanisms, J Neurosci. 29 (2009) 5873-5883.

\section{Figure Legends}

Fig. 1. Comparison of amino acid sequences and forced expression of recombinant mouse Neucrin in cultured cells. (A) Comparison of amino acid sequences of mouse Neucrin and human NEUCRIN. The numbers refer to amino acid positions. Asterisks indicate identical amino acid residues in the sequences. Underlined sequences indicate putative secreted signal sequences and cysteine-rich domains. Dashes indicate gaps introduced to align sequences. (B) Comparison of amino acid sequences of a cysteine-rich domain of mouse Neucrin and the second cysteine-rich domains of mouse Dkk1 and Dkk2. The numbers refer to positions of cysteine residues indicated by open boxes. (C) CHO-S cells were transfected with the empty vector (Control) and the mouse Neucrin-expression vector (Neucrin).

Fig. 2. The expression of Neucrin in mouse adult tissues, embryos, and embryonic and postnatal brains. (A,B) Neucrin expression in adult tissues and embryos was examined by RT-PCR (A). Neucrin expression in mouse brain at different developmental stages was examined by RT-PCR (B). The expression of Gapdh was also examined as a control. (CF) The localization of Neucrin mRNA in embryos. Sagittal sections of mouse embryos at E13.5 (C,D) and E18.5 (E,F) were examined by in situ hybridization with an ${ }^{35}$ S-labeled antisense $(\mathrm{C}, \mathrm{E})$ or sense $(\mathrm{D}, \mathrm{F})$ mouse Neucrin $\mathrm{RNA}$ probe. Red grains superimposed upon a hematoxylin-eosin stain show the localization of neucrin mRNA. Scale bars $=5$ $\mathrm{mm}$. 
Fig. 3. Binding of Neucrin to the extracellular domains of the LRP6 receptor and degradation of $\beta$-catenin by Neucrin. (A) Neucrin-Myc binding to Brorin-IgG, Fz8CRDIgG or LRP6N-IgG. Neucrin-Myc CM was added after Brorin-IgG, Fz8CRD-IgG or LRP6N-IgG in CM was pre-bound to ProteinA-sepharose. (B) 293T cells were pretreated for $3 \mathrm{~h}$ with either control or Neucrin CM, and then treated with Wnt3a protein for a further $2 \mathrm{~h}$. $\beta$-catenin and $\beta$-actin levels were determined by Western blotting. 


\section{Fig.1}

A

mouge MAGCPVLRVPTLFLILLLFPELHTAGTLASGSSARNLPETHSHLPSSALWVSQASHHGRRGLGKKDRGP 70 human MAGPAIHTAPMLFLVLLLPLELSLAGALAPGTPARNLPANHIDLEGPALWTPQASHHRRRGEGKKEWGPG 70

mouse RPSRAQEGAVVSATKQASQMTLG ........PPAGLLQNKELLLGLTLPYPEKEARSPGWERVKKRGREHK 134 human LPSSQÄDGAVVTATROAASRLPEABGLLPEQSPAGLLODKDLLLGLALPYPEKBNRPPGWERTRKRSREHK 140

MOUSE RRRDRLRLHRGRAAIRGPSSLMKKVEPSBDRMLEGTMEESSTSLAPTMFFLTMADGATPTTEESRILPVT 204 human RRRDRLRLHOGRALVRGPSSLMKKAELSEAQVLDAAMEESSTSLAPTMFFLT-TFEAAPATEESLILPVT 209

mouse SLRPQ -TQPRSDGEVMPTLDMALFDWTDYEDLKPEVWPSAKKKEKHWSHFTSDGNETSPABGDPCDHHOD 273 human SLRPQQAQPRSDGEVMPTLDMALFDWTDYBDLKPDGWPSAKKKEKHRGKISSDGNETSPAEGEPCDHHOD 279

mouse CLPGTCCDLRBHLCTPHNRGLNNCFDDCMCMBGLRCYAKFHRNRRVTRRKGRCVEPETANGDQGSFINI 343 human CLPGTCCDLREHLCTPHNRGLNNKCFDDCMCVEGLRCYAKFHRNRRVTRRKGRCVEPETANGDQGSFINV 349

B

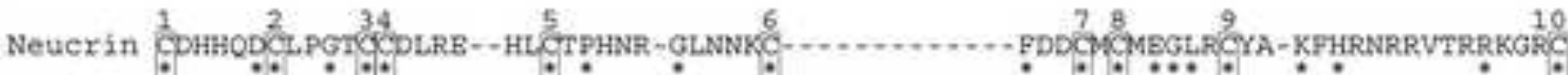

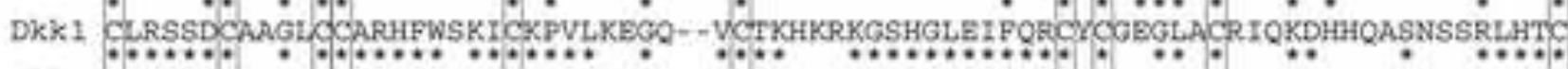
DKk2 CLRSSDCIDGFCCRHFWTKISKPVLHOGE - VGTKQRKKGSHGLEIFQRCDCAKGLSCKWWKD-ATYSSKARLHVC

C

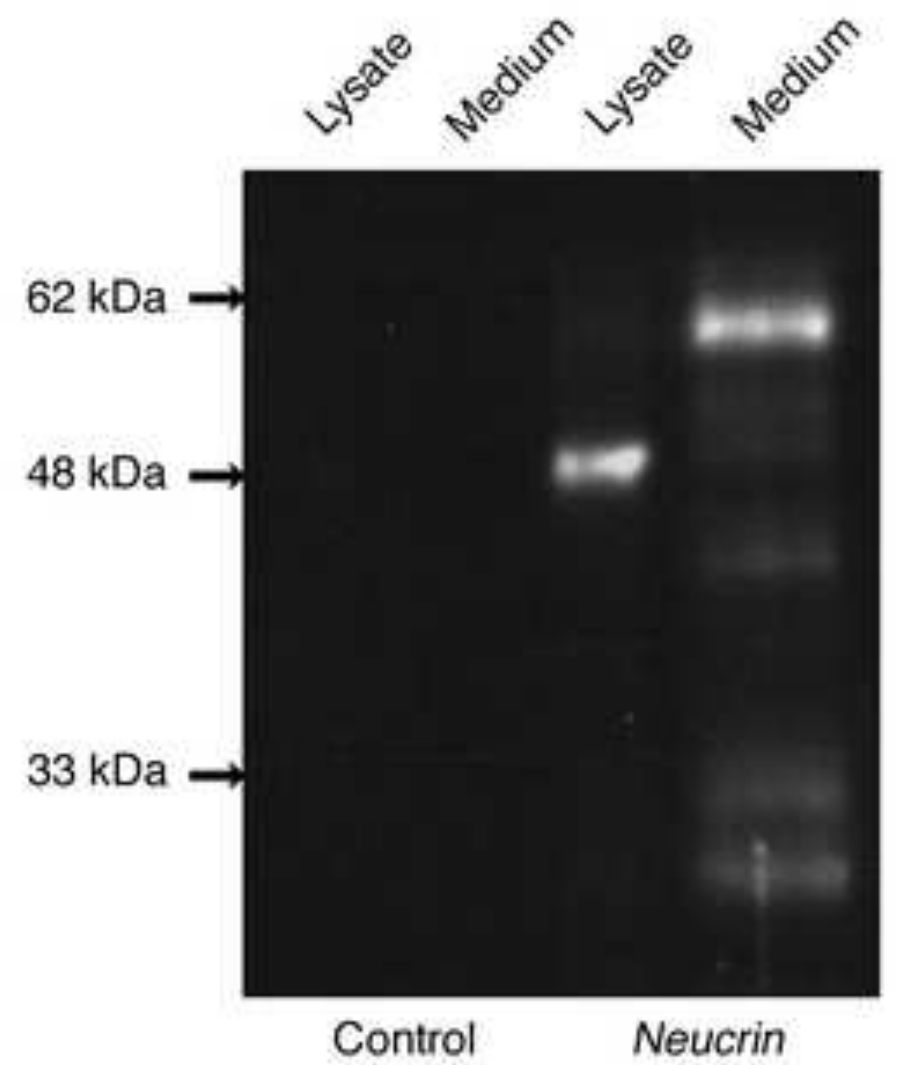


Fig.2

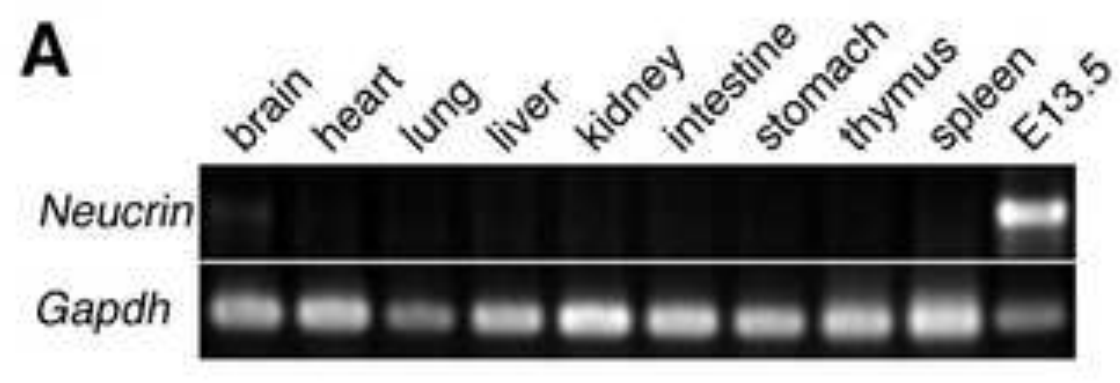

B
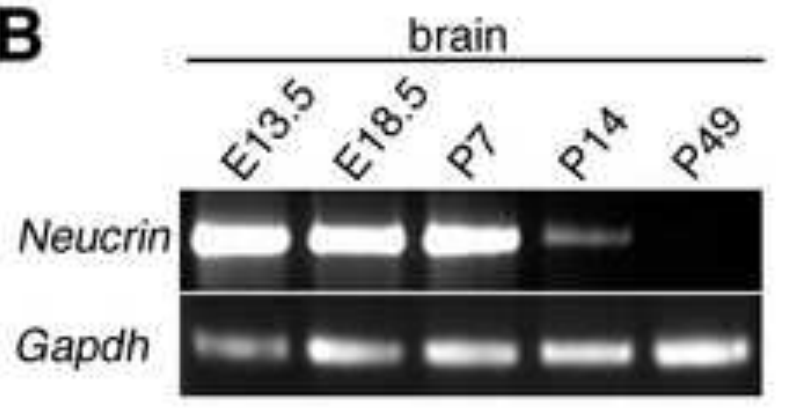

C

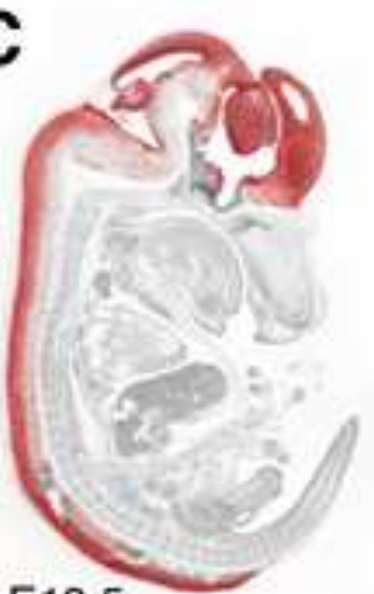

D

E13.5

E

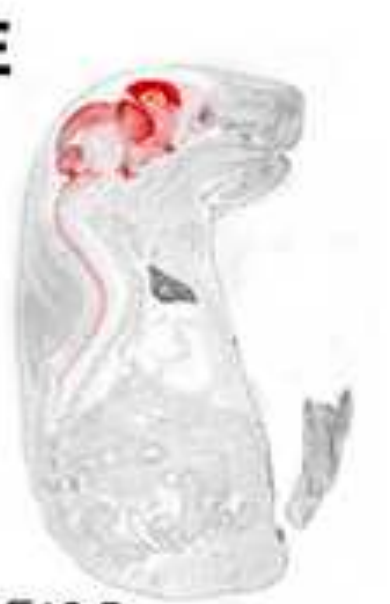

E18.5

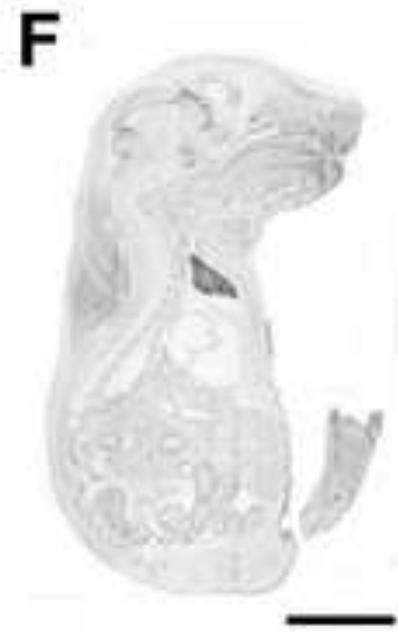

\section{E13.5}

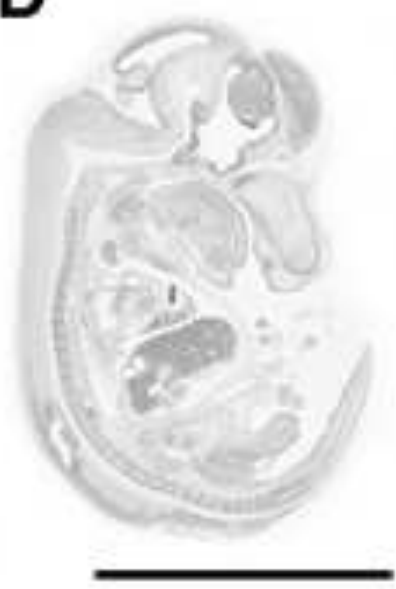


Fig. 3

A
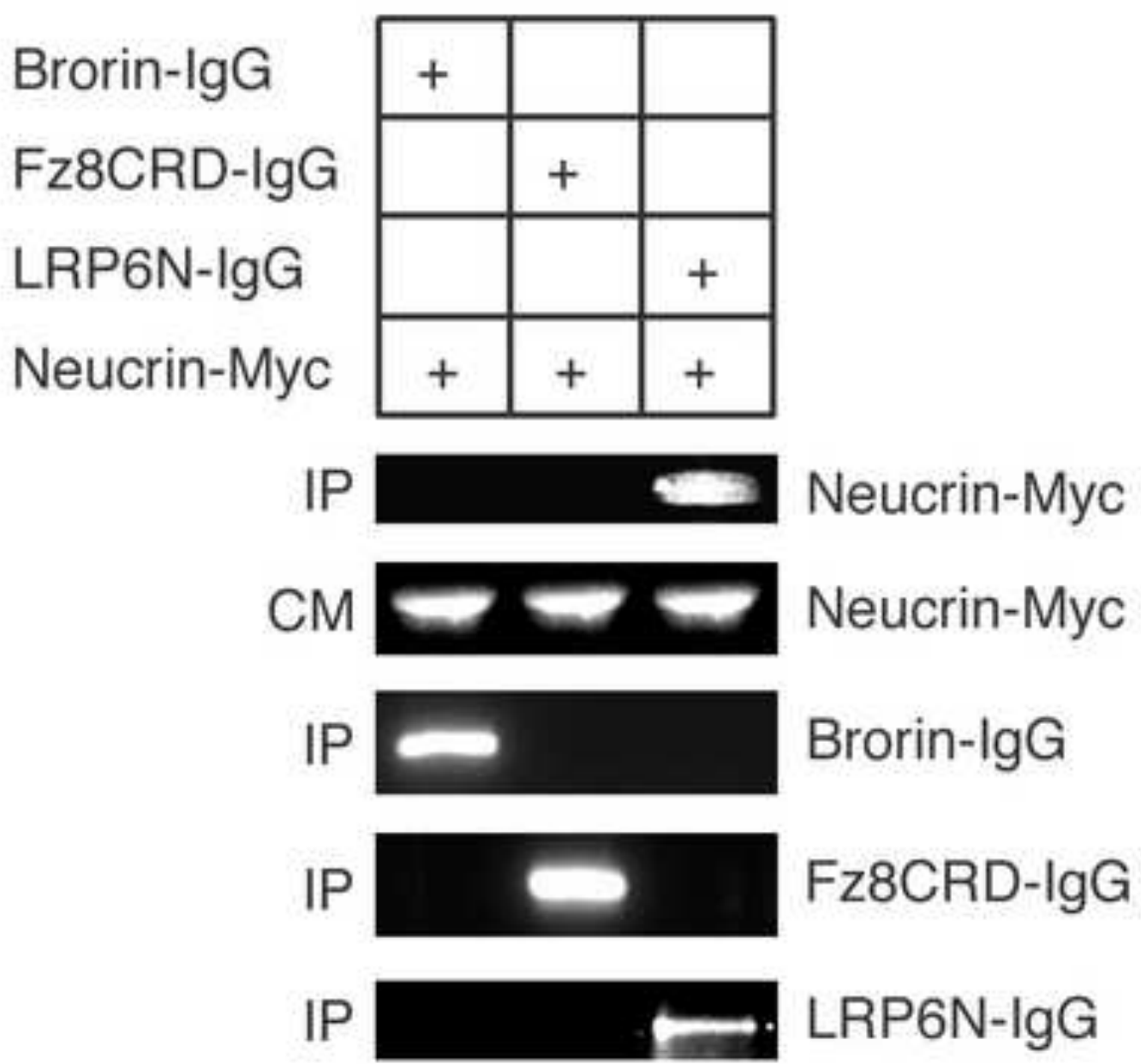

B
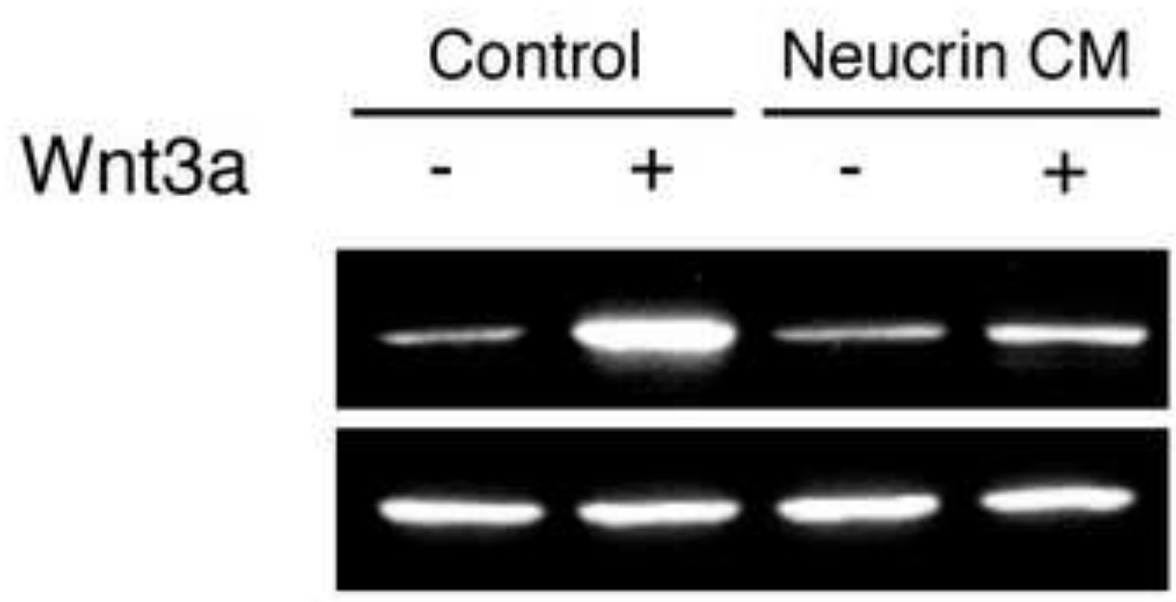

$\beta$-catenin

$\beta$-actin 